Geopolítica(s) Revista de estudios sobre espacio y poder ISSN: 2172-3958

\title{
Tradición, agonía y consenso en la Geopolítica brasileña entre 1930 y $1964^{1}$
}

\author{
João Catraio Aguiar²
}

Recibido: 3 de mayo de 2017 / Aceptado: 24 de marzo de 2018

Resumen. El propósito principal de este artículo es discutir la producción intelectual individual y colectiva desde la Revolución de 1930 hasta el momento en que las Fuerzas Armadas tomaron el poder. Tiene la intención de aclarar las principales ideas que se impusieron en el período y que tendrían impacto en el país en momento histórico posterior. Los métodos empleados fueron: el análisis histórico e institucional; la interpretación del pensamiento de actores y autores prominentes; una mirada de las interacciones e afinidades entre personas y/o grupos. La principal conclusión es que en la geopolítica brasileña de 1930-1964, hubo dos tradiciones principales: podría distinguirse entre los "de acción" (licenciados, "isebianos" y políticos) y los "de la palabra" (ingenieros, militares y diplomáticos). Si el "consenso" imperaba dentro de cada uno de los grupos, entre ellos, imperaba la "agonía", el conflicto. Palabras clave: Geopolítica; pensamiento político; Brasil; tradiciones geopolíticas.

\section{[en] Tradition, Agony and Consensus in the Brazilian Geopolitics between 1930 and 1964}

\begin{abstract}
The main purpose of this article is to discuss the individual and collective intellectual production from the 1930 Revolution to the moment when the Armed Forces took power. It has the intention to clarify the main ideas that prevailed in the period and that would affect the country in a further moment. The methods employed were the historical and institutional analysis, the interpretation of prominent actors and authors and a glance on interactions and/or groups. The main conclusion is that in 1930-1964 Brazilian geopolitics there were two main traditions: it would be possible to distinguish between the "of action" (graduates, "isebianos", and politicians) and "of word" (engineers, militaries, and diplomats). If a "consensus" reigned inside each of these groups, between them reigned the "agony", the conflict.
\end{abstract}

Keywords: Geopolitics; foreign thought; Brazil; geopolitical traditions.

1 Me gustaría agradecer a Leticia Pinheiro, mi supervisora de Doctorado, su orientación, que crea siempre condiciones para el crecimiento intelectual. Agradezco a mis estimados profesores Maria Regina Soares de Lima y Carlos R. S. Milani, por sus consejos, orientaciones y por motivarme a escribir lo que hoy es ese artículo. El entonces asistente Gregor de Rooy también me ayudó mucho.

2 Universidad Estadual de Rio de Janeiro. Becario de CAPES

E-mail:.jjhhccmmaa@gmail.com 


\section{[pt] Tradição, agonia e consenso na Geopolítica brasileira entre 1930 e 1964}

Resumo. O propósito principal desse artigo é discutir a produção intelectual individual e coletiva desde a Revolução de 1930 até o momento em que as Forças Armadas tomaram o poder. Tem por intenção aclarar as principais ideias que prevaleceram no período e que teriam impacto no país em um momento posterior. Os métodos empregados foram: a análise histórica e institucional; a interpretação do pensamento de atores e autores proeminentes; um olhar sobre as interações e afinidades entre pessoas e/ou grupos. A principal conclusão é que na geopolítica brasileira de 1930-1964 houve duas tradições principais: poder-se-ia distinguir entre os "de ação" (bacharéis, "isebianos" e políticos) e os "da palavra" (engenheiros, militares e diplomatas). Se o "consenso" imperava dentro de cada um dos grupos, entre eles, imperava a "agonia", o conflito.

Palavras-chave: Geopolítica; pensamento político; Brasil; tradições geopolíticas.

Sumario. Introducción. 1. Recordando la Geopolítica en el Norte y el Sur. 2. Las principales corrientes geopolíticas brasileñas hasta mediados de los años 1960. 2.1. Los "opus populi": ingenieros, militares, diplomáticos. 2.2. Los "verbum populi": licenciados, "isebianos" y políticos. Conclusión. Bibliografía.

Cómo citar: Aguiar, João Catraio (2018) “Tradición, agonía y consenso en la Geopolítica brasileña entre 1930 y 1964”. Geopolítica(s). Revista de estudios sobre espacio y poder, vol. 9, núm. 1, 87-111.

\section{Introducción}

Este trabajo se ocupa de la producción de conocimiento en los centros globales del poder y en la periferia. Serán presentadas de forma sintética las principales maneras de pensar la geopolítica que resultaron en la génesis del campo de estudio.

La segunda parte comienza ocupándose de los “opus populi”’3, hombres más de acción que fundaron la Geopolítica en Brasil y/o fueron influyentes entre 1930 y mediados de los años 1960, para después, abordar la cuestión de los "verbum populi", intelectuales importantes también en la fundación de la Geopolítica. Es decir, no será considerada toda la producción antes de la Revolución de 1930 y del golpe de Estado de 1964. Este trabajo se centrará más bien en la discusión sobre la producción individual; sin embargo, tanto la Escuela Superior de Guerra (ESG) como el Instituto Superior de Estudios Brasileños (ISEB) son cruciales para la comprensión del período porque, en cierta manera, se trata de organizaciones que orientaron la selección de los trabajos que iban $-\mathrm{O}$ no- a integrar este proyecto.

Hay mucho que comentar sobre esa cuestión, especialmente con relación a la importancia del tema ante estrategias a medio y largo plazo, tanto para los países que presentan mayor grado de ventajas relativas en relación a otros, como para los que presentan menor grado. En cuanto a la metodología escogida, se pretende trabajar a través de los métodos interpretativo e historiográfico.

3 El término opus populi es utilizado para referirse a las personas que toman decisiones y desarrollan sus ideas en estrecha conexión con su actividad profesional, mientras los verbum populi son personas cuyas ideas resultan de su formación intelectual y/o de una supervivencia basada en la movilización de palabras, narrativas, ideas, etc. 


\section{Recordando la Geopolítica en el Norte y el Sur}

Para encontrar el origen del término geopolítica hay que remontarse al cambio de siglo, del XIX al XX, cuando Rudolph Kjéllen (1864-1922) acuñó el concepto. En aquel período de muchos imperialismos y de expansión territorial de Estados con más poder (sobre todo el globo), muchas disciplinas científicas surgieron y/o se consolidaron. Muchos leyeron el autor escandinavo, así como otros trabajos en Biología, Geografía y Antropología, y resultaron fuertemente influenciados por la idea de evolución.

Cuando Friedrich Ratzel (1844-1904) inició su producción académica, la influencia del evolucionismo era cada vez más evidente. El enfatizó la importancia del crecimiento estatal, la expansión más allá de las fronteras que se inicia con el pueblo buscando su seguridad y desarrollo, seguido del ente orgánico que lo representa: el Estado (Ratzel, 2011 [1896]). Karl Haushofer (1869-1946), por su parte, fue un hombre influyente en la Alemania de entreguerras al difundir la Geopolítica, ya sea en la Universidad de Múnich, donde impartió clases a través del Instituto de Geopolítica, ya sea en la revista Zeitschrift für Geopolitik, dedicada al tema. Según el geopolítico alemán, el "espacio vital" es en donde se encuentran los recursos, la cultura y el pueblo. Por eso, se debe garantizar su seguridad, que es base de la supervivencia y desarrollo del Estado (Haushofer, 2012 [1927]). El también sería influyente en la política de aproximación germánica con los japoneses y la de no agresión con los soviéticos.

En la época de entreguerras en Alemania, la pedagogía del conflicto y las creencias milenaristas y/o revolucionarias llenaban los vacíos del trauma de la Primera Guerra Mundial. Este hecho, junto con la percepción de una conspiración de enemigos, conforman el escenario sobre el cual ocurrió gran parte de la socialización política, de la formación intelectual y del compromiso/filiación por parte de los nazis más jóvenes (Ingrao, 2015). Por lo tanto, no fue solamente un grupo prominente de intelectuales muy cercanos de los círculos decisorios más elevados de la Alemania Nazi los que procedieron de acuerdo con la "politización de saberes", sino también una masa de afiliados y partidarios que no siempre se destacaban. La geopolítica germánica se convertía en una "Ciencia de Estado" al servicio de la expansión imperialista y tuvo por lo menos tres cursos sucesivos: la proliferación en modelos semejantes en otros países, el uso académico y/o militar en distintos sitios y la crítica (Cairo, 2011). En el mundo anglosajón los orígenes de la geopolítica clásica estaban vinculados a la academia y al medio militar.

Durante la Segunda Guerra Mundial, se conoce una metodología de análisis holístico constituida por diversas técnicas, como el uso/la producción de estadísticas, mapas, etc. que, cuando es utilizada de modo flexible, lleva a comparaciones, no a leyes (Cahnman, 1942). En Estados Unidos, al mismo tiempo que autores como Werner Cahnman (1902-1980) defienden la evolución de la geopolítica, nacen las primeras críticas a la "Ciencia de Estado" germánica.

En los EE UU, Alfred Mahan (1840-1914), hijo del rector de la Academia Militar con sede en Nueva York y militar de la Marina de los Estados Unidos, destacó que, en términos de seguridad, el hecho de no tener fronteras terrestres ofrece ventajas defensivas y los mares propician el comercio y las comunicaciones entre los países. Por ello se debe estimular el poder naval (Mahan, 2013 [1890]). El geopolítico considera la extensión territorial, el tamaño de la población y el tipo de gobierno como 
vitales en el desarrollo y en la defensa nacionales, bajo una visión que relaciona la guerra con la economía. Tiene una concepción de que la proyección naval depende de la existencia de bases navales.

En Gran Bretaña, la Real Sociedad Geográfica ya existía cuando Halford Mackinder (1861-1947) innovó la Geopolítica, pero todavía sin enfatizar la expansión terrestre como Haushofer y su "espacio vital" o el "poder naval" y la expansión en mares y océanos según Mahan. El pensador británico ve un área que comprende Rusia, la parte de Asia Central, de Europa Oriental y de Oriente Medio como "pivote" - que es de difícil acceso, pero que se puede atacar distintos lados- en Eurasia (Mackinder, 2010 [1904]). Sus ideas serían divulgadas en ambientes académicos y políticos, como Oxford, London School of Economics y el Parlamento Británico. La historia, la seguridad y el desarrollo de Europa dependerían de detener el avance de amenazas situadas en el Heartland, en el área pivote, y que una alianza realista en defensa de la democracia debería prevalecer. Para asegurar esos objetivos, los hombres de Estado también deberían investir en la ampliación de las capacidades de movimiento y comunicación.

De la misma manera que muchos autores clásicos de estrategia y geopolítica dieron un valor excesivo al poder terrestre (Haushofer, Mackinder y otros) y, en contraste, muchos más enfatizaron el poder naval (Alfred Mahan, por ejemplo), también es necesario recordar que hay una teoría del poder aéreo. El italiano Giulio Douhet (1869-1930) fue uno de los pioneros en lanzar la idea del "dominio del aire". En su obra con ese título comenta que el poder aéreo surgió como soporte y, con el tiempo, se hizo importante en el campo de batalla, ofensivamente hablando, por bajar la moral de los oponentes, por ser difícil detener sus ataques, por ser útil en escenarios de guerra por mar y tierra, por los bombardeos en ciudades con civiles y por hacer con que los ataques a "puntos vitales" vuelvan inútiles las defensas (Douhet, 1942). No será el único autor, aún a finales de 1920, en defender el uso coordinado de diferentes fuerzas armadas. Estos pensamientos preceden el argumento para que, más adelante, ocurriera la consolidación del comando civil sobre los militares, y además, fuesen creados los Ministerios de Defensa. Su libro tomó como base el análisis de la Primera Guerra Mundial y su experiencia como militar.

El holandés arraigado en Estados Unidos Nicholas Spykman (1893-1943) retoma el debate de Mackinder poniéndolo en nuevos términos. Conforme a sus ideas, la localización mundial del Estado define sus enemigos y aliados potenciales, los límites de su papel y la naturaleza del territorio limítrofe, así como su tamaño (Spykman, 1938a). El no solamente reconoció la importancia de factores históricos y políticos en la localización regional. También reflexionó acerca de que tales factores son fundamentales para que el país tenga poder terrestre o naval (Spykman, 1938b). Pensó en una gran estrategia que mezclara las políticas internas con la externa y la militar, incluso en momentos de paz y de guerra, a través de la cual todo el globo sería tomado en consideración, una vez que se comprenden las relaciones entre las distintas regiones del mundo. Para el equilibrio del poder mundial, lo más crucial sería dominar el camino circunferencial marítimo (Rimland), o el Creciente Interno de Mackinder (Costa, 2013).

Spykman proponía una supremacía de los Estados Unidos sobre las Américas que incluyera el Panamericanismo económico, militar y político, y tejió una crítica tanto al orden mundial conquistado por agresión por el Eje como a la cooperación liberal de la Sociedad de las Naciones. Además, dijo que la propuesta estadounidense es de 
orden mundial, que no excluye una organización política global de patrones federales y que demanda integración que no excluya estadounidenses de zonas transoceánicas (Spykman, 2008 [1942]). Mientras Ratzel y Haushofer proponían un modelo en dirección de la autarquía de y de la expansión de unos Estados frente a otros - tal como la idea de dominar el Heartland por Mackinder, que también es expansionista-, Spykman enfatizaba una participación del Estado para la contención de una eventual potencia, deteniendo su poder en su entorno, en el Rimland. Sus trabajos fueron influyentes después de su muerte, en la Guerra Fría.

En Francia, las influencias de la Historia y la Filosofía preponderaron y se puede decir que allí surgió una "escuela clásica", con un origen distinto de la que surgió en Alemania y en Estados Unidos. En Alemania, prevalecía la visión, asociada el determinismo, de que la naturaleza era predominante sobre el hombre. Sin embargo, en Francia el pensamiento geográfico estaba dominado por el posibilismo, simbolizado en las obras de Vidal de La Blache, que veía el paisaje como correlacionado a la contingencia y a la libertad del hombre, que moldea la naturaleza (Moraes, 2005). Después de la generación de La Blache, Réclus y Vallaux, la producción geopolítica francófona se enriquece con la producción de André Siegfried y Jacques Ancel. Si la escuela germánica mantuvo mayor énfasis en la totalidad y en el Estado, la escuela francesa - que, a su vez, también se afirmó - analizaba más las regiones defendiendo la mutua influencia entre política y espacio. Así, se destacó el "diatope" de Yves Lacoste, que fue una herramienta de análisis geopolítico a múltiples escalas en superposición. La revista Hérodote influyó en la producción académica geopolítica francesa desde los años 1970, y eso estimuló trabajos de discusión que entrelazaban geografía e ideología (Lacoste, 2011b). Jean Gottman también está relacionado con esas discusiones cuando defendió que el comportamiento de las naciones era condicionado, pero no determinado, por las condiciones geográficas (Gotmann, 1951).

Respecto a esta "escuela" francesa de geopolítica, destaca el uso de cartografía, como en el estudio sobre la "guerra ecológica" emprendida en Vietnam del Norte y las funciones político-estratégicas de la geografía (Lacoste, 2011a [1976]). En Francia, se destacaron muchos pensadores marxistas estructuralistas y postestructuralistas después de la Segunda Guerra Mundial. Uno de los más destacados fue Henri Lefebvre. Él veía tres etapas del capitalismo (comercial, industrial y mercado mundial capitalista) y veía los principales impulsos a los conflictos y contradicciones globales en las desigualdades halladas en el moderno modo de producción estatal (Lefebvre, 2012 [1976]). Estrategias y luchas surgen en función de esos obstáculos. Un ejemplo es la que hay entre los centros y las periferias. Para el pensador francés, la producción del espacio interconecta aspectos mentales (representaciones ideológicas), físicos (geográficos) y sociales (prácticas) y, dando movimiento a su pensamiento, que hay diversos tipos de espacio y sobre ellos inciden diferentes energías en diversos tiempos (Lefebvre, 1974). Otro autor reputado en términos de análisis geopolítico marxista es Immanuel Wallerstein. Su análisis de sistemas-mundo se basa en el argumento de que la acumulación y la distribución son desiguales en el mundo, y eso genera el proceso de periferización, por el cual determinadas zonas son expropiadas por el capitalismo mundial en ciclos de expansión y contracción (Wallerstein, 1982).

La lucha en contra de esas asimetrías, para los marxistas (en el centro y en la periferia), pasa por diversas acciones para alcanzar una nueva hegemonía. Hay todavía producciones geopolíticas que no se enfocan ni en temas estatales ni en temas 
sistémicos, sino que se centran en cuestiones transnacionales y subnacionales. Esta tradición marxista de la geopolítica muestra que hay similitudes en la trayectoria de diferentes ideologías, posicionamientos políticos, etc. Si hay una geopolítica conservadora, que pretende mantener el poder como está y/o expandirlo, hay una corriente más combativa, crítica y tan plural como era la producción clásica y la de las "escuelas".

Más tarde, vino la "geopolítica crítica", que se propuso analizar lo que se produjo en términos geopolíticos y la manera en la que los estadistas se apropian de las cuestiones geográficas para sus agendas (Criekemans, 2011). Los críticos presentaron la interconexión entre geopolítica y desarrollo, arrojando luz sobre los flujos y movimientos que actúan sobre el espacio (Ó Tuathail, 1994). Los posmodernos también consideran que cualquier producción política está ligada a una narrativa, y que todas estarían en contienda entre sí. El grupo "posmoderno" o "crítico" trae debates sobre el conocimiento al centro que en la periferia ya se estaban realizando, sin mencionar, reconocer o criticar autores periféricos.

Incide sobre las narrativas geopolíticas el clivaje entre los núcleos del poder (centro) y los sitios en donde hay escasez del mismo y lagunas de capacidad (periferia). A lo largo del periodo analizado, entre los años 1930 y 1960, hubo grandes transformaciones internacionales (la Segunda Guerra Mundial, la Guerra Fría y la Descolonización, por ejemplo) y, en esta contextualización, algunas zonas se clasificaban en centrales (América Anglosajona, Europa Occidental) y otras en periféricas (América Latina, África y la mayor parte de Asia). ¿Por qué es relevante comprender lo que se piensa en los territorios del Norte? Mucho de lo que allá se produce es recibido por los países en el Sur Global, en donde se sitúa el Brasil. Entonces, para comprender el pensamiento brasileño de geopolítica es necesario reconstituir esas teorías hegemónicas.

Desde otro ángulo, la condición periférica puede ser un estímulo para el surgimiento de productos intelectuales autóctonos presentando soluciones políticosociales, unas veces por un sesgo cosmopolita, otras por nacionalista (Lynch, 2013). La circulación de ideas dentro de un espacio contiguo puede hacer que surjan "escuelas de pensamiento", como sucedió entre los latinoamericanos con la CEPAL, durante la década del 1940, y después con la teoría de la dependencia (Garcia, 2006). El circuito académico de las regiones periféricas ayudó en la internacionalización de la producción y circulación del conocimiento, pero es necesario avanzar en esa senda para que el Sur Global se vuelva más desarrollado y mejor conocido (Beigel, 2013). Hay, por lo tanto, al menos tres grandes diferencias entre el Norte y el Sur: A) el modo cómo circula/se produce el saber; B) las condiciones estructurales y dinámicas de dónde surgen las ideas, y $\mathrm{C}$ ) las funciones reales que asume el pensamiento.

Hay algunos debates geopolíticos clásicos en la periferia, generalmente de "orden práctico", sobre técnica y estrategia, mientras que en las zonas céntrales se produce la discusión sobre la "guerra total", como en Clausewitz (1988), o sobre qué tipo de Fuerza Armada es más eficaz. En las áreas en desarrollo se producen propuestas de insurgencia asimétrica. Esta práctica existe desde hace muchos años, como se puede ver en la actuación de Juan Martín Díez, el Empecinado (1775-1825), en la España del comienzo del siglo XIX. Sin embargo, la guerra de guerrillas, que asocia métodos no convencionales de combate con el objetivo de revolucionar la estructura sociopolítica (Guevara, 1980), es mejor conocida con el trabajo de Ernesto "Che" Guevara (1928-1967). 
Un segundo debate es "sistémico", es decir, sobre el ordenamiento del poder, nacional e internacionalmente. Hay narrativas que agregan e interpretaciones individualistas sobre las situaciones en el Sur. Por un lado, existen los autores que entienden la disputa por el poder político, las condiciones económicas y los demás factores como regulados por las mismas lógicas, independientemente de la localización del Estado. Son las teorías realistas, en términos politológicos e internacionalistas, neoclásicas en términos económicos $\mathrm{y}$, por fin, conservadoras en términos sociales. Por otro lado, hay los que consideran la situación en la periferia muy semejante entre ellos y diferente de los centros. Son, por lo tanto, lógicas distintas. En ese grupo están las teorías críticas en términos politológicos e internacionalistas, las perspectivas nacional-desarrollistas en términos económicos $\mathrm{y}$, en términos sociales, las propuestas marxistas y las ideas liberales.

Poniéndolo en términos sencillos, en el Sur existe un grupo más cercano de la perspectiva occidental, del capitalismo y del desarrollo asociado, mientras que hay otro que tiene una perspectiva tercermundista, afroasiática y/o latinoamericana, de un desarrollo endógeno. Mientras uno defiende una geopolítica de asociación o de acercamiento crítico al Occidente, sea como sea, del otro lado se encuentran los que pretenden transformar el país en un polo socialista o más cercano al bloque comunista. Durante la Guerra Fría, hubo incluso un grupo de no alineados, que se propuso rechazar ambas propuestas $\mathrm{y}$, con ello, crear otras configuraciones que dieran más prominencia a la periferia y la semiperiferia. En ese grupo destacaron los liderazgos de Sukarno, Tito, Nasser, Nehru, entre otros. Además, la noción geopolítica de agregación de las naciones en bloques es anterior al periodo seleccionado para este artículo.

Los pensadores idealistas del comienzo del siglo discutían si la postura (geo)política debería volverse hacia soluciones autóctonas o si se debería defender la civilización. En 1900, José Enrique Rodó (1872-1917) defendía la razón y la civilización, la democracia humanitaria como intereses de la especie (Rodó, 1985 [1900]), aboliendo, por lo tanto, las distinciones entre el Sur Global y los países centrales. Ya en 1913, José Ingenieros (1877-1925) proponía una política generada por individuos idealistas, para superar la fase de hombres inferiores y mediocres. Para ello, sería necesario tener buenas condiciones socioeconómicas y que la elite genial rechazara al imperialismo (Ingenieros, (2008 [1913]). Algunos años después, en 1925, José Vasconcelos Calderón (1882-1959) decía que en Iberoamérica se debería producir la "raza cósmica", mediante la mezcla de pueblos de todos los continentes, viabilizando el apogeo humano y civilizacional (Vasconcelos, 1948 [1925]). Junto a la crítica al racismo y el enaltecimiento al mestizaje, ésta es una propuesta de convivencia harmónica entre países llenos de diversidad. Uniendo esas tres narrativas se puede tener las variadas propuestas de unión entre países de las Américas: ora para defenderse de la explotación, ora para volverse más occidental, ora para llegar a un ideal todavía no conocido en la práctica.

Un tercer debate es "relacional", y se desarrolla principalmente en la producción intelectual de América Latina y África. Concierne al modo en cómo determinados países o determinadas colectividades en condiciones subalternas deben $-\mathrm{O}$ noproceder. Las semillas de variados panamericanismos, paneslavismos, de unificación europea, de unificación entre miembros de una misma religión y las demás formas de unidad ya existían. No sería distinto en el caso africano. Después de la Segunda Guerra Mundial, Patrice Lumumba (1925-1961) en sus discursos les 
pediría a los africanos que se unieran para crear condiciones en el continente para poner fin a las injusticias y la dominación (Lumumba, 2013). De hecho, la defensa del panafricanismo fue realizada por diversos líderes: Amílcar Cabral, Jomo Kenyatta, Marcus Garvey, Modibo Keïta, Kwame Nkrumah y Samora Machel, entre otros. La lista sería mucho más larga, si se incluyera a personas con actividad posterior a 1964, límite cronológico de ese artículo.

Otras voces que se pronunciaron en esa misma frecuencia fueron las de los teóricos de la negritud Aimé Césaire (1913-2008) y Léopold Senghor (1906-2001). Para ellos, la opresión cultural y política es sufrida por los no blancos y la clave de salida de la condición colonial sería luchar por la nación e identidades del continente africano (Césaire, 1955). Denunciando la falta de conciencia nacional, las nefastas consecuencias sobre la salud de los colonizados, la Guerra Fría, el uso de armas de destrucción masiva, la miseria y el subdesarrollo, Frantz Fanon propone nuevas instituciones, nuevos pensamientos y defiende regionalismos — como la Liga Árabe y el Panafricanismo- y la lucha de liberación, que sirven como medios para acabar con las cosas que él critica (Fanon, 2003). Si sumamos esas propuestas a los Congresos Panafricanos organizados en la primera mitad del siglo XX, nos podemos hacer una idea del panorama de movilización por la descolonización afroasiática. Pasada la Segunda Guerra Mundial, muchos países se organizaron de forma independiente, y eso impactó en la geopolítica global.

También existe, por último, la crítica al modo de vivir en el Occidente desarrollado, como en el caso de la Ecología Profunda, que algunos dicen remitir a conocimientos ancestrales, como el de las nociones teológicas del africano "Ubuntu" o el asiático "Namasté". En ambos casos, es el reconocimiento de que uno convive con el otro en harmonía, y que la humanidad convive en equilibrio con todas las formas vivas y naturales. Como diría Lope de Vega, "Ni el rey comería si el labrador no labrase". Esas ideas ya existían en el período que va de los años 1930 a los 1960 , pero los libros y tertulias dedicados a estos temas solamente ganaron mayor repercusión el presente siglo.

La discusión sobre el desarrollo estaba más enfocada a la dimensión material, casi como una reacción al idealismo de la Belle Époque. Uno de los mayores polos de discusión se situaba en Chile. Era la Comisión Económica para América Latina (CEPAL) de las Naciones Unidas, que realizaba investigaciones desde los años 1940. Al defender la industrialización, la planificación económica estatal, la inversión estatal en políticas sociales y el estrechamiento de las relaciones entre periféricos, Raúl Prébisch (1971) criticó el sistema global que hacía que los latinoamericanos sufriesen el deterioro de los términos de intercambio. Autores "cepalinos" propusieron una economía más orientada a su propia región, con la sustitución de importaciones, el control de la inflación y su comercio exterior orientado hacia los vecinos.

Después de recordar algunos debates que se han producido en la periferia, se puede ver lo productivo de sus propuestas geopolíticas, que tienen perfiles más bien distintos que semejantes a las de los países centrales. La realidad se acerca a lo que pensaba Mohammed Ayoob (1998), para quién toda teoría tiene estrecha conexión con la época y con el lugar donde es producida. Tal vez debamos resaltar lo que importa la persona y su trayectoria en la producción de conocimiento.

En cierta medida, el Brasil va a recibir ambas tendencias, pero tendrá como principal objetivo el análisis del mundo en función del propio país. Lo que diferencia a 
los autores brasileños de los demás del Sur Global, en ese periodo, es una posición poco decidida, a veces nebulosa, en relación a qué bloque pertenecía el país, qué perfiles autónomos podría presentar o qué procesos serían más adecuados. Pero precisamente por las muchas dudas existentes fue una época muy prolífica. Ahora veremos cómo se dio ese desarrollo de la geopolítica en Brasil, siguiendo a sus principales pensadores entre 1930 y 1964.

\section{Las principales corrientes geopolíticas brasileñas hasta mediados de los años 1960}

Los orígenes del debate sobre la geopolítica de Brasil pueden ser identificados en dos grupos ${ }^{4}$ clave: los "verbum populi" (licenciados, "isebianos" y políticos) y los "opus populi" (ingenieros, militares y diplomáticos). En general, el primer grupo está asociado a un debate teórico y/o ideológico, al mismo tiempo que el segundo elabora sus obras a partir de la experiencia real. Pero hay otras diferencias que aparecen a lo largo del texto y se incluyen en la conclusión.

\subsection{Los "opus populi": ingenieros, militares, diplomáticos}

Los ingenieros constituyen el primer grupo que hará Geografía Política y Geopolítica en el país. El mítico Euclides da Cunha (1866-1909) ya consideró las relaciones sociopolíticas vinculadas a la tierra y los dilemas de la modernización en el país. El ingeniero consideraba que en el espacio brasileño hay dos culturas/sociedades - la del interior/pastoril y la zona litoral/urbana - y estas dimensiones de lo arcaico y de lo moderno generan un conflicto en la Guerra de Canudos: la relación hombre-tierra. Por lo tanto, vistas desde el prisma determinista (Bôas, 2006: 41-58). En otros análisis, como sobre la Amazonia, sobre la eurasiática Rusia, sobre el conflicto entre Bolivia y Perú, etc., transluce una visión general sobre la modernización y la civilización que fue influenciada por la lectura de las realidades rusa y estadounidense, y parecía trascender el optimismo con el "centro" y el pesimismo con la "periferia" (Maia, 2008). Él era militar, vinculado a la cancillería del Barón de Río Branco, y gozaba de una buena reputación entre los "verbum populi" republicanos.

Otro eminente ingeniero fue el esperantista Everardo Backheuser (1879-1951). Ya había habido debates sobre los temas del territorio y su capital en el ámbito político, como atestigua Afrânio de Melo Franco, pero aún no se había encontrado una solución definitiva. Trabajando con las teorías de espacio, forma y posición, Backheuser (1933) define como prioridades para la unidad nacional la revisión territorial, según el principio de "igual potencia", y el traslado de la capital brasileña hacia una zona más central, saliendo de Rio de Janeiro. Él comenta que algunas zonas son "políticamente ficticias", es decir, los mares, los desiertos y bosques densos, que no pertenecen a la ecúmene, no son "terreno político", pero con respecto a los

\footnotetext{
4 En el país, hasta los años 1950, el analfabetismo ascendía a más de 50\% de la población. Por lo tanto, los geopolíticos pertenecían a la élite. La presencia de autores licenciados en Derecho e Ingeniería no es casualidad, una gran parte de los graduados de aquella época eran en esas áreas o en la de Medicina. Otros cursos se consolidaron a lo largo de todo el siglo.
} 
“ámbitos políticos" y citando el Marqués de Paraná, sostiene que cada parte del país debe ser equivalente a las demás (Backheuser, 1933). En el capítulo II de su libro existe un plan de división territorial. Propone la meseta de Goiás como un lugar para el cambio de la capital, donde debería haber un Distrito Federal que albergara los poderes del Estado.

El pensamiento militar es algo antiguo, se remonta al debate sobre la estrategia, en particular acerca de la guerra, viendo el espacio de modo más táctico, distinto de Backheuser, más enfocado sobre el análisis de Euclides da Cunha sobre Canudos. Las escuelas militares en Brasil se remontan, algunas veces, al período colonial y, en ocasiones, al imperial. Desde mediados del siglo XIX, los militares buscaron más protagonismo en la política, lo que lograron en diversos momentos: en la Guerra del Paraguay, a lo largo de la Proclamación de la República, en la época del Tenentismo, durante la participación del país en las dos guerras mundiales, en la Revolución de 1930, en la presentación de candidaturas de (ex)militares para cargos públicos en la República de 1946 y en cualquier intento de desestabilizar y/o estabilizar ciertos gobiernos. El cuerpo castrense, por lo tanto, estaba en constante movimiento, hasta que asumió el poder en 1964, derrocando a los poderes democráticos y legítimos en aquel entonces. Hay otros ejes, además de la presencia en la política, que influyen en la forma en la que se produce el pensamiento entre los militares: la existencia de un esprit de corps dentro de las organizaciones, las misiones y escuelas militares y la incidencia de "doctrinas" externas, como el positivismo.

Desde el punto de vista del debate estratégico y del mantenimiento de un debate que favorecía la recepción de la geopolítica alemana, se puede decir que la revista $A$ Defesa Nacional fue importante. Oficiales germanófilos fundaron la revista en 1913, con la traducción de artículos en otros idiomas, incluidos el alemán, pensando en la forma de modernizar, principalmente, el Ejército Brasileño (Lemos, 2013). Había un grupo de militares que produjo obras relevantes en términos geopolíticos y tuvieron gran influjo no sólo en la República de 1946, sino también después en su desmontaje.

Mário Travassos (1891-1973) participó en la Fuerza Expedicionaria Brasileña y fue comandante de la Academia Militar de las Agujas Negras. Como militar influyente en la Geopolítica, escribió Aspectos Geográficos Sudamericanos en 1931 que, tras revisión y extensión, pasó a llamarse Proyección Continental do Brasil ${ }^{5}$. A la segunda edición - datada en 1935, ya presentando el nuevo título- le fueron agregados el prefacio de Pandiá Calógeras, en donde se recomienda a los "hombres de gobierno" el estudio del material, y el apéndice que establece conexión con la nota inicial, en donde se indica que se trataba, en palabras de Ronald de Carvalho, del "primer ensayo de geopolítica en Brasil". La obra de Travassos se construye a partir de los artículos publicados previamente.

Según Travassos (1935: 17-26), hay dos diferencias principales concernientes a América del Sur - Atlántico vs. Pacífico y Amazonas vs. Plata- que tienen una influencia sobre cómo Brasil debería diseñar su poder. Identifica como principales puntos de preocupación política: en América del Sur, Bolivia, por el antagonismo Atlántico-Pacífico; en el plano de la Amazonia, Colombia, y en el plano platino, Uruguay (Travassos, 1935: 61-78). El "triángulo boliviano" (Cochabamba, Santa

Debido a la rareza de la obra, no ha sido posible trabajar con la $1^{\text {a }}$ edición. Sin embargo, todas las ediciones posteriores tienen el mismo título de la $2^{\mathrm{a}}$ edición y el debate sobre Travassos gira en torno a ella. 
Cruz de la Sierra, La Paz) es solicitado por todos los lados. Y la presencia yanqui se extiende a todos los países americanos, especialmente en América Central y Caribe que, de acuerdo con el geopolítico, oscilan entre las maniobras diplomáticas y los golpes de fuerza estadounidenses. En el caso de las Guayanas, está presente la influencia europea también, no sólo la norteamericana. Por lo tanto, la Amazonia y el Pacífico son los dos cuadrantes con mayor presencia de las grandes potencias. Sugiere el argumento del libro que, para su proyección continental, el Brasil debería desarrollar su infraestructura, detener inquietudes, coordinar los cuadrantes y neutralizar otras influencias.

Hay, también, en el período comprendido entre la Revolución de 1930 y la Constitución de 1946, otros autores que influyeron en el debate geopolítico: Francisco Paula Cidade trabaja en el análisis de las potencialidades de todos los países de América del Sur en 1934; Raja Gabaglia, quien defendió el determinismo geográfico; Leopoldo da Fonseca, que en 1940 decía que a la ascensión nacional brasileña solo se oponían las "doctrinas subversivas"; Lysias Rodrigues - discípulo de Backheuser y de Travassos-, quien abogaba por la construcción de un núcleo geopolítico en América del Sur bajo el liderazgo brasileño y por la presencia en las fronteras, en particular aquellas con Argentina, Bolivia, Ecuador y Perú (Miyamoto, 1996: 64-75). Igualmente hay que destacar la creación en 1938 del Instituto Brasileiro de Geografia e Estatística (IBGE), desde el que se lanzan la Revista Brasileira de Geografia en 1939 y el Boletim Geográfico en 1943.

Mientras Travassos buscaba la proyección estratégica, hacia fuera, Golbery buscó contención estratégica, volviendo el análisis hacia dentro. En otras palabras, mientras que el primero acogió a Mackinder, el segundo leyó a Spykman (Costa, 2013). Golbery do Couto e Silva (1911-1987) tiene artículos publicados entre 1952 y 1960, que han sido recompilados en su obra Geopolítica do Brasil de 1967. Los artículos son: "Aspectos geopolíticos del Brasil" (1952, 1959, 1960); "Geopolítica y geoestrategia" (1959); "Dos polos de la seguridad nacional en América Latina" (1959); "Areas internacionales de entendimiento y áreas de roce" (1959), y "Brasil y la defensa de Occidente" (1958). En su libro, Couto e Silva (1967) se presenta como un realista occidental al criticar idealismos utópicos, considerándose el equilibrio de poder como el principio pragmático del sistema interestatal, y aclara que los conflictos tienen dimensiones psicosocial, política, económica, militar y tecnológica.

Para el entonces teniente coronel, ese escenario requiere que la estrategia se incorpore en la política de seguridad nacional ${ }^{6}$, y la defensa de Occidente y sus características (Democracia, Ciencia y Cristianismo) se deberían de enfatizar por parte de Brasil, que sería la potencia occidental por excelencia en América del Sur, evitando así las amenazas de la guerra nuclear, la guerra localizada y la guerra subversiva (Silva, 1967: 217-258). A los Estados Unidos, así como a los países occidentales en general, competiría asistir en la lucha contra el subdesarrollo en la región, en particular el Brasil porque los sudamericanos - los brasileños, particularmente - se comprometerían con el combate al Oriente. El antagonismo dominante entre Oriente y Occidente fuerza esa solidaridad en las Américas, pero, más allá de ella, él

6 Aquí es oportuno decir que Golbery y los "esguianos" fundadores consideraban la Defensa como algo estrictamente militar y la Seguridad Nacional sería algo más amplio, con la participación de otras expresiones del Poder Nacional. 
recomienda las solidaridades "del mundo atlántico" con países lusófonos, latinos, católicos y, finalmente, subdesarrollados.

La lógica de Golbery es la de los círculos concéntricos de pertenencia, entendimiento y solidaridad, y que dentro del propio país debería haber la misma unidad, considerada por él como necesaria entre los occidentales. El espacio y la posición brasileña exigen mayor integración territorial, al principio vinculando el Sur hacia el Noreste; después avanzando a la plataforma central, ocupando las fronteras y ríos en el Norte y en el Centro-Oeste, y, finalmente, participando en la geopolítica del Atlántico Sur y Sudamérica continental (Silva, 1967: 19-94). En el interior debe haber, según Couto e Silva, expansionismo; en el exterior, una proyección pacífica. En el interior deben contenerse las amenazas; en el exterior debe haber proximidad y colaboración con Occidente y con los países subdesarrollados, especialmente en el espacio sudamericano y atlántico. Tenía su pensamiento influenciado por el vitalismo de Toynbee y su concepto de civilización, el realismo de Morgenthau y sus conceptos de poder e interés nacional, y Spykman y su geopolítica (Gonçalves, 1984).

En 1955, lanzó el libro Planejamento estratégico, que arroja luz sobre las relaciones entre Estrategia y Geopolítica. En la obra se expone la necesidad de realizar la planificación estratégica de la seguridad nacional, a fin de garantizar la soberanía y la racionalización del Estado. Para Couto e Silva (1981), planificar implica la comprensión de los objetivos permanentes y actuales y potenciales, analizar la situación, hacer un estudio del espacio geoestratégico (zonas), construir escenarios hipotéticos de conflicto y proporcionar un sistema jerarquizado de las decisiones. Existe una estrategia de seguridad nacional que cumple acciones en paz y en guerra, y, así, se construyen el concepto y las políticas para alcanzar los objetivos (Silva, 1981). En este libro se aplica la teoría de los juegos y la cibernética, así como se emplean autores de la Sociología, Economía y Estrategia/Geopolítica.

No era infrecuente la interpenetración de algunos de los elementos constitutivos de los grupos citados entre sí. En el caso de Juárez Távora (1898-1975), él estuvo en la frontera entre los "opus populi" y los "verbum populi" porque era militar e ingeniero, pero pertenecía al Partido Demócrata Cristiano - el mismo que apoyaba Jânio Quadros-y tuvo varios puestos importantes, como el de ministro. El entonces General Juárez Távora, en el año de su derrota, publica Petróleo para o Brasil, donde sostiene que, en términos teóricos, lo ideal sería la nacionalización de la explotación petrolera. No obstante, en la práctica, se deben solucionar los requerimientos internos para el producto. Así pues, el camino intermediario sería el esquema de concesión que permita la explotación con predominio de capitales nacionales (Távora, 1955). Esta propuesta garantizaría que Petrobras, la empresa petrolera nacional, no fuera víctima de la corrupción, que no hubiera una interferencia de otras potencias sobre nuestros recursos naturales y que el país llegara a una situación de no tener que importar/exportar hidrocarburos. El autor se refiere en varias ocasiones a Alberto Torres y Oliveira Vianna, así como a Golbery.

A continuación, todavía afrontando cuestiones energéticas, pero también de producción y transporte, escribe Produção para o Brasil en 1956. Sostiene que el Brasil debe bajar los costos de transporte, conectar los núcleos dispersos, racionalizar los ferrocarriles, puertos y carreteras y ampliar la movilidad en las zonas urbanas. Estas actitudes ampliarían la cohesión interna y la seguridad nacional. Para mejorar la situación económica del país no bastaría con modificar la circulación, sería necesario 
aumentar la producción a través de la electrificación, acudiendo a fuentes de energía hidroeléctricas, solares, atómicas, químicas y eólicas (Távora, 1956). En su opinión, el desarrollo y bienestar del país están vinculados a estas decisiones.

Habiendo sido jefe de la Casa Militar y miembro del Consejo de Seguridad Nacional en el gobierno Café Filho (1954-1955), fue llamado para asistir a una Comisión Parlamentaria de Investigación (CPI) de la Cámara de Diputados Federales en 1956, poco después de su derrota por Juscelino Kubitschek (PSD) en la elección de 1955, por el PDC y apoyado por la UDN. El libro de 1958, titulado Átomos para o Brasil, es una compilación de su exposición a la CPI, que es la investigación a que le sometieron, y una glosa sobre todo lo que ocurrió, bajo su perspectiva. No hay muchas propuestas, porque es casi una exposición de su inocencia frente a las alegaciones.

En 1959, publica Organização para o Brasil, que utiliza el método de la Escuela Superior de Guerra y defiende la puesta en valor de los municipios, incluso proponiendo cambios territoriales, estatales y municipales. Él propone un nuevo poder, el "ordenador", que coordinaría a los otros tres Poderes, y aboga por la introducción del parlamentarismo. En términos de seguridad nacional, dice que es necesario, a nivel interno, modernizar las fuerzas armadas, aplicar el plan y las operaciones combinadas, generar movilización nacional. A nivel internacional, él recomienda la participación en la ONU y la OEA, dentro de la seguridad colectiva internacional, con el compromiso de evitar el daño a cualquiera de los miembros de la coalición del continente americano (Távora, 1959).

El ciclo de publicaciones de la época se cierra con Uma política de desenvolvimento para o Brasil, de 1962, que también utiliza la metodología "esguiana", dándose cuenta del desarrollo como progreso en todas las "expresiones del poder nacional": político-administrativo (incluyéndose los poderes militar y diplomático), económico-financiero y psicosocial (incluyéndose la ciencia y la tecnología).

El primer capítulo analiza las potencialidades naturales de todo el Brasil, identificando los puntos fuertes y débiles, lo que se repite para los demás capítulos, cada uno para cada una de las expresiones. Ese libro recoge propuestas ya formuladas en trabajos anteriores, y toma el valor de la vida humana como el principal factor de desarrollo nacional, teniendo como ejemplos lo que se hizo en Japón, con la Revolución Meiji, en el Imperio Ruso, justo antes de su caída y después con la Unión Soviética, seguido por los logros de la Alemania Occidental después de 1945 (Távora, 1962).

La producción de Távora no termina en la colección de libros "para el Brasil" porque fue uno de los fundadores (junto con Cordeiro de Farias, Salvador Obino, Idálio Sardenberg, Golbery do Couto e Silva, entre otros) de la Escola Superior de Guerra (ESG) y su doctrina. En su origen, la ESG debería ofrecer cursos para el Alto Mando del Ejército, de acuerdo con la ley de 1942, pero en 1948 se extiende al personal militar de todas las Fuerzas, y un grupo, de más o menos diez personas, establece los principios, bajo la influencia de National War College de los Estados Unidos. Los fundadores pensaron en edificar conceptos para orientar los principios y los medios de poner en práctica las soluciones nacionales a los problemas en Brasil, puesto que no sería una institución solo para estudiar el conflicto bélico. Con la nueva ley de agosto de 1949 se establece la institución militar que existe hasta hoy, 
con las características de sus fundadores y dos cursos: uno solo para militares y otro con plazas para civiles y militares.

Al inicio, en la ESG había tres sectores de estudios (nacional, internacional y militar). En 1954 se disuelven y, en su lugar, se crean cuatro departamentos de estudios (político, económico, militar y psicosocial), a los cuales se añade en 1961 el de "Doctrina, Ciencia y Tecnología". Según Antônio Arruda (1983), la ESG pasó por distintas etapas: la primera (1949-1952) está marcada por un énfasis en el Análisis de Coyuntura; la segunda (1953-1967) está marcada por la búsqueda de la Seguridad Nacional; la tercera etapa (1968-1973) tiene el Desarrollo como motor principal de estudios y creciente desapego de la influencia estadounidense; y la cuarta fase, que se extiende hasta el día de hoy, es la de los Manuales Básicos y de una revisión sustantiva del cuerpo doctrinal "esguiano". La lista de las personas que habían tenido contacto con la ESG como estudiantes en prácticas, conferenciantes, dirigentes, directores, etc., es sumamente amplia y se puede decir que fue muy influyente en el período analizado.

Sea porque la Escuela - también conocida informalmente como "la Sorbona"se comportaba como "partido funcional", el caso es que fue una institución orientada a la formación de cuadros y a la acción del Estado, que se preocupaba, resultado del pensamiento conservador predominante, por el Orden (Ferreira, 1979). El linaje político conservador apostó por la unidad territorial y se centró en la actuación regional en la cuenca del Plata con el Vizconde de Rio Branco, las fronteras con el Barón de Rio Branco, el pacto de Brasil con Argentina y Chile (ABC) con Lauro Müller, que se inició con su predecesor, y en todo el período de 1840 a 1930, con mayor o menor intensidad, se dio una buena relación con los Estados Unidos (Aguiar, 2015). Los liberales también se significaron posteriormente, ya sea en grandes campañas políticas con temática internacional, ya sea en sus actuaciones en relación con la política comercial, en general, que estaban más orientadas a los países occidentales que a América del Sur. Los linajes políticos —o tradiciones políticas cómo decía Pocock (2009) - tuvieron un momento de gran crecimiento con las obras del Barón de Rio Branco, Joaquim Nabuco, Ruy Barbosa, y otros en esa época

El diplomático, político y empresario José Carlos Macedo Soares (1883-1968) trabajó intensamente en la mediación diplomática entre los países sudamericanos y entre Brasil y los intereses empresariales de São Paulo. Cubierto de un liberalismo que se tornaba conservador, era uno de los nombres del anticomunismo brasileño mientras Vargas estuvo vivo. Era una voz en favor de un Occidente liberal y defendía el Estado de derecho, la importancia del derecho tanto en la diplomacia como en la inserción internacional y la interconexión entre la diplomacia y la historia. Como defensor de las tradiciones patrias, estudió las fronteras coloniales (Conduru, 2013), y también tuvo actuaciones en el campo de la museología y describió el papel de Brasil en la Liga de las Naciones. El diplomático João Augusto de Araújo Castro (1919-1975) también se destacó en Itamaraty por las reflexiones sobre integración internacional. Según Costa Vargas (2008), en dos momentos históricos, 1945 y 1990, la diplomacia brasileña se dividió según dos orientaciones, la americano-occidental y la universal-desarrollista; Araújo Castro se alineaba en la segunda y defendía la autonomía estatal, el desarrollo económico y la actuación multilateral.

En una ponencia pronunciada en la ESG en 1958, acerca del Poder Nacional y sus limitaciones, destaca las vulnerabilidades de Brasil. El entonces Ministro de Segunda Clase explicita cuáles son las limitaciones internas: las características 
geográficas -aunque adoptaba una postura crítica con el "geografismo" (determinista) de Ratzel, Haushofer, Mackinder y Spykman-, la escasez de alimentos, de petróleo y uranio, la baja industrialización y la escasez de población aparecen. En cuanto a las limitaciones externas, señala que la más importante es el poder nacional de otros países, en particular de las grandes potencias - aquí reafirma su realismo - en un escenario de bipolaridad, que, en un conflicto de posiciones, esteriliza el poder de "neutros, no alineados y terceras fuerzas". Alianzas, acuerdos y compromisos limitan la acción exterior, así como los ámbitos supranacionales, trusts y cárteles (A. Castro, 1982). La manera de fortalecer internamente el poder nacional sería el desarrollo, con especial énfasis en la Ciencia y la Tecnología, y externamente habría que perfeccionar la diplomacia y el sistema de seguridad regional. En 1963, uno de los momentos de mayor brillantez de la diplomacia multilateral brasileña, Araújo Castro recogió en un discurso las tres "Des" claves para el Brasil: el Desarme, el Desarrollo Económico y la Descolonización. Esto significaba acercarse, si se reforzara una de las "Des", a los países subdesarrollados y comunistas, lo que era una línea de acción brasileña que se hizo explícita en ese momento.

\subsection{Los "verbum populi": licenciados, "isebianos" y políticos}

Las tradiciones expresadas entre los militares brasileños, los diplomáticos de Itamaraty y los ingenieros, a menudo formados en la Escuela Politécnica, no son las únicas. Muchos licenciados y literatos se posicionaron geopolíticamente y tienen su propia trayectoria. Entre los literatos se destaca Olavo Bilac (1865-1918), quien se pronunció en favor de la "militarización de civiles" para luchar contra el "militarismo", de la instrucción física asociada con la intelectual en favor de la patria y de una defensa nacional más liberal y democrática (Bilac, 1965 [1915-1916]). La Liga de Defensa Nacional fue creada en 1916, con el objetivo de buscar seguridad y paz, y tuvo líderes como Miguel Calmon y Pedro Lessa. Bilac se preocupaba especialmente por el civismo y el nacionalismo.

El licenciado Oliveira Vianna analiza el perfil de los brasileños — que tienen una unidad territorial a pesar de las grandes diferencias entre el medio campesino (más realista) y las zonas urbanas (más idealistas) - a partir de tres tipos sociales: el aldeano, el gaucho y el pueblerino (Vianna, 2005 [1920]). Proponía la construcción de un Estado fuerte para asegurar esa difícil unidad territorial. Las dificultades geográficas e históricas podrían superarse con el nacionalismo, el patriotismo y una política orgánica — con protección y equilibrio para todos los sectores de la sociedad - según Alberto Torres (1914: 3-152), quien fue gobernador del estado de Rio de Janeiro y Ministro de Justicia.

Curiosamente, los tres citados (Torres, Vianna, Bilac) son inmortales en la Academia Brasileña de Letras. Décadas más tarde, alcanzó el honor de la inmortalidad académica Helio Jaguaribe, que empezó a ser un personaje influyente al participar del suplemento cultural de la página 5 del diario Jornal do Commercio, publicado los viernes, que incluía a varios intelectuales de renombre: Helio Jaguaribe, Candido Mendes, Augusto Frederico Schmidt, Oscar Lorenzo Fernández, Israel Klabin, entre otros. Las publicaciones del suplemento del Jornal do Commercio comenzaron en julio de 1949 y continuaron hasta aproximadamente 1952. 
Después, Jaguaribe sería uno de los líderes del Grupo de Itatiaia que, desde 1952, reunía a intelectuales, a mitad del camino entre São Paulo y Rio de Janeiro ${ }^{7}$. En el grupo participaron: Helio Jaguaribe, Guerreiro Ramos, Rômulo de Almeida, Ewaldo Correia Lima, Candido Mendes, Oscar Lourenço Fernandes, Ignácio Rangel, José Ribeiro de Lira, Israel Klabin, Cid Carvalho, Fábio Breves, Ottolmy da Costa Strauch, Heitor Lima Rocha, Vicente Ferreira da Silva, Paulo Edmur de Souza Queiroz, Ângelo Simões de Arruda, Almeida Salles, José Luiz de Almeida Nogueira Porto, Miguel Reale y Luigi Bagolin. Pretendían asesorar al gobierno para generar desarrollo nacional, y contaban con el apoyo del Ministerio de Agricultura, debido a la influencia de Rômulo de Almeida.

Jaguaribe fue abogado en un despacho de Rio de Janeiro, y fue uno de los fundadores del Instituto Brasileiro de Economia, Sociologia e Política (IBESP), daría diversos cursos y mantendría el clima de debates sobre cuestiones nacionales. La revista Cadernos do Nosso Tempo fue publicada por IBESP entre 1953 y 1956, y giró en torno a los debates presentes en los grupos previos. En general, los diferentes números presentaban un análisis de coyuntura, debates teóricos y propuestas de solución de problemas, especialmente de la realidad brasileña.

Entre sus artículos se destaca "Para uma Política de Desenvolvimento Nacional" de 1956, que introduce varios conceptos (por ejemplo, la estructura estándar, la fase, la autenticidad, la ideología, etc.) que aparecen en los trabajos posteriores de Jaguaribe. En este artículo de más de 140 páginas, se analiza el contexto económico, político y social de Brasil, y propone cambios en el Estado y en la administración estatal (IBESP, 1956). En el mismo volumen, hay un artículo sobre el golpe de Estado en Argentina y sobre el intento de golpe de Estado en Brasil, todos en tono de crítica, lo que pone de manifiesto la actitud progresista de Jaguaribe.

En el gobierno Café Filho, en julio de 1955, se creó el Instituto Superior de Estudios Brasileños. La estructura se componía de un Consejo Consultivo formado por 50 personas $^{8}$, debajo de ellos estaba el Consejo Curador ${ }^{9}$, en seguida estaba el Director Ejecutivo, Roland Corbisier, y abajo estaban los directores Helio Jaguaribe (Ciencia Política), Ewaldo Correia Lima (Economía), Álvaro Vieira Pinto (Filosofía), Candido Mendes (Historia) y Guerreiro Ramos (Sociología).

El lanzamiento del libro $O$ nacionalismo na atualidade brasileira de Helio Jaguaribe fue motivo de discordia entre los fundadores del Instituto a finales de 1958. Guerreiro Ramos, imbuido del deseo de expulsar a Jaguaribe del ISEB, propagó la idea de que el trabajo era antinacionalista, aunque tras una deliberación interior se definió lo contrario. Ramos no aceptó ver que Jaguaribe no sería expulsado y dimitió. Esto provocó una profunda división en el grupo nacionalista y, a continuación, se produjo una reforma del estatuto, motivo por el cual Jaguaribe pidió su salida. Después de las dos salidas, el ISEB salió de sus enfrentamientos y actuó más

7 En aquel momento, Roland Corbisier era profesor de la USP y Helio Jaguaribe era profesor en la PUC-Rio. Los intelectuales de São Paulo tendían a la derecha y muchos eran ex “integralistas”. Los de Rio de Janeiro tendían hacia la izquierda, algunos estaban cercanos al gobierno laborista de Vargas (1951-54) y algunos al marxismo.

8 En el libro Ideologias e segurança nacional de Guerreiro Ramos (1957) se encontraban casi cincuenta nombres en el Consejo Consultivo.

9 Consejo Curador compuesto por: Adroaldo Junqueira Aires, Anísio Teixeira, Ernesto Luiz de Oliveira Junior, Hélio de Burgos Cabal, Hélio Jaguaribe Gomes de Mattos, José Augusto de Macedo Soares, Roberto de Oliveira Campos y Roland Cavalcanti de Albuquerque Corbisier. Temístocles Brandão Cavalcanti también participó de ese consejo. 
coherentemente (Sodré, 1978). Se puede considerar que el ISEB pasó por las siguientes "fases": la primera fue el origen, que va hasta 1955; la segunda fue la de estabilidad, entre 1955 y 1958; la tercera, la de los cursos extraordinarios, y la cuarta, hasta el año 1964, con la publicación de los Cadernos do Povo Brasileiro (Pereira, 2005). No podemos ocuparnos aquí de toda la producción del ISEB, sin embargo, hay tres autores cuyos análisis son fundamentales para la geopolítica y, en un sentido más amplio, el desarrollo: Guerreiro Ramos, Helio Jaguaribe y Roland Corbisier.

Alberto Guerreiro Ramos se posicionó sobre temas geopolíticos en el libro de 1957 publicado por ISEB. Según el sociólogo, cualquier ideología debe entenderse en su funcionalidad, de manera científica, evitando las visiones ingenuas que se centran en los aspectos ideológicos como forma absoluta y maniquea. Desde mediados del siglo XIX hasta la década de 1930, la élite definía la seguridad nacional, a partir de elementos que todavía provenían de la época colonial/semicolonial. Después de 1930, el pueblo participa de la toma de decisiones, mientras la nación se industrializa, así que se cambia la percepción estatal. Autodeterminación, independencia y desarrollo (centrípeto) son los nuevos objetivos de la seguridad nacional (Ramos, 1957). Sobre el papel que debe tener la seguridad nacional frente a los antagonismos, Guerreiro Ramos (1957: 44-50) subraya que internamente se debe actuar en contra de cualesquiera tipos de presiones que amenacen o neutralicen sus actividades y externamente se deben aprovechar las oportunidades, consolidando el poder nacional y el desarrollo.

Helio Jaguaribe publica en el ISEB, Condições institucionais do desenvolvimento, escrito a partir de dos conferencias en el Club de Ingeniería en 1957. En él, el autor critica al "Estado Cartorial" 10 y el clientelismo, que mantenía el carácter del país como exportador de recursos primarios e importador de manufacturas, y aseguraba el parasitismo social y la baja productividad (Jaguaribe, 1957). Entre las soluciones para la superación de la estructura estándar semicolonial y, para lograr una buena transición, señalaba la movilización en torno al desarrollo nacional acompañada por una planificación democrática que siga en esta dirección y tenga legitimidad, tanto en el plano estatal como en el plano social.

A continuación, también publica en el ISEB el libro $O$ nacionalismo na atualidade brasileira, que se dividía en dos partes: la primera, se ocupaba de cuestiones teóricos, y la segunda se centraba en problemas específicos. Tras una fuerte discusión, dialéctica sobre lo nacional, Jaguaribe señala las cuestiones más importantes del nacionalismo brasileño - a la luz de lo que se pensaba en aquel momento-: se debería preocupar por la competitividad, por un funcionalismo sin "cartorialismo" y por una actuación del capital nacional en el caso del petróleo, propugnando un Consejo Nacional de Petróleo como organismo regulador y la Petrobras como una instancia empresarial (Jaguaribe, 2005 [1958]: 97-145). En términos de capital extranjero, sería necesario permitir la libre circulación de capitales, con un límite establecido de repatriación global de beneficios, organizar el mercado nacional de capitales y crear condiciones por medio de una institución

10 Es posible caracterizar el "Estado Cartorial” cómo lo que es estructuralmente corrupto, tiene fuerte jerarquía sociopolítica, y está basado en la venta de empleo por votos y viceversa. Así que "cartorialismo" se refiere a las acciones que se dan en el ese tipo de Estado. El concepto es una creación de Jaguaribe y una crítica a la combinación de bajo desempeño estatal — que nada ayuda en el desarrollo — con la administración que se sirve solamente a si misma y a los que detentan el poder. 
pública para que las inversiones prosperen en el país (Jaguaribe, 2005 [1958]: 146199).

La política exterior debería, según Jaguaribe, buscar primeramente el desarrollo - y, por lo tanto, superar el debate sobre si debería lograr con los EE UU, con los países anticoloniales o con los latinoamericanos - de forma neutral e independiente, evitando alistarse en el americanismo occidental. En esta composición, Argentina tendría un papel geopolítico vital (Jaguaribe, 2005 [1958]: 200-267). En muchas de sus publicaciones, Jaguaribe describe cómo debería ser la integración internacional posterior, con la superación del carácter de país exportador primario, con presencia en la ONU y en América del Sur, acercándose a los países continentales, anticoloniales y vecinos (Guimarães, 2015).

Roland Cavalcanti de Albuquerque Corbisier fue el organizador de un ciclo de ocho conferencias en Brasilia, en el ISEB, muy importante desde el punto de vista geopolítico $^{11}$. A raíz del subdesarrollo colonial, se desarticuló el territorio y predominó la alienación cultural, la producción para el exterior, las capitales costeras descentradas, el trabajo agrícola y la política clientelar. Sin embargo, cambiábamos, al integrarse el país en torno a la nueva capital, desarrollándose la conciencia, el desarrollo, la cultura auténtica, la producción para el mercado interno (sustituyendo importaciones), la industria nacional y la política ideológica (Corbisier, 1960). Así, el desplazamiento al interior de la metrópoli podría reducir las contradicciones entre centro-periferia del país, llevando el progreso a las regiones no costeras, y creando condiciones para una mayor unificación de América Latina.

Es importante destacar la relevancia de dos personas que no eran ni del ISEB ni de la ESG, pero marcaron época debido a los valores que aportaron a los debates acerca de la geopolítica. La primera es Josué de Castro, quien puso el debate sobre el hambre en el mapa. Según su estudio, Brasil tenía entonces cinco zonas alimentarias: las zonas de la Amazonia y del Mato Grosso, que padecen hambre endémica permanente; el Sertão (región semiárida) del Nordeste sufre epidemias de hambre, de carácter transitorio; y las zonas del Centro y del Sur tienen desnutrición, asociadas a ciertos grupos y clases, pero no padecen hambre.

La razón de la hambruna en el país se debe, según su interpretación, al mantenimiento de la agricultura extensiva de exportación, que servía a los intereses privados y extranjeros y no a los nacionales, como sí lo hacía la agricultura intensiva de subsistencia (J. Castro, 1946). Como solución, cabrían plantearse el desarrollo, la reforma agraria y la afirmación de la alimentación del pueblo como un objetivo.

En un libro posterior, el hambre es diseccionada en una variedad de matices (hambre oculta, falta de proteínas, falta de minerales o falta de vitaminas) y se analizan su distribución a través de todos los continentes del mundo. Para evitarla, sería necesaria una lucha mundial contra el hambre (J. Castro, 1955 [1950]), que debería combatirse por ser una fuente de enfermedades, por estar en el origen de las guerras y por reforzar el atraso económico. La lucha implicaría el aumento de la productividad del suelo - con un mejor control de plagas y enfermedades-, la mayor utilización de fertilizantes, la mejor alimentación de ganado y rebaños, avances en bioquímica y genética, dominio de la producción de alimentos en los

11 El libro Significación geopolítica de Brasilia estaba en la lista de próximas publicaciones relacionadas con el ciclo. No se pudo encontrar ejemplares de este libro, cuyo autor fue Josué de Castro. 
mares, ríos y lagos, la equiparación de lo que se produce con la distribución y el consumo de alimentos, la extinción de latifundios, monocultivos y otros factores de falta de productividad. Por último, a nivel mundial, se debería avanzar en el proceso de emancipación colonial completo, y establecer la reciprocidad de intereses económicos.

Francisco Clementino de San Tiago Dantas es el siguiente autor destacado, que, como Jaguaribe y Golbery, pensó la inserción internacional de Brasil a la luz de su poder nacional. Perteneció al Partido Laborista Brasileiro, del que fue fundador Getúlio Vargas y líderes importantes João Goulart y Guerreiro Ramos ${ }^{12}$. En sus conferencias como orador en la ESG, sus preocupaciones geopolíticas incluían: Problemas del Extremo Oriente (1951), la Alianza del Atlántico Norte y la Unión de Europa Occidental (1952), Inversiones Extranjeros en Brasil (1953).

La comprensión de la política internacional, de la que se ocupó la primera conferencia, debería pasar por el conocimiento de los procesos políticos y económicos de las zonas vecinas del país y de las zonas dominantes del mundo y, en consecuencia, se propugnaba la utilización del enfoque de los estudios de área, junto con el método histórico y comparativo. Se analizaban Japón, China, Mongolia y la República de Corea.

La segunda conferencia se centró en la Seguridad Regional en Atlántico Norte, afirmándose que la mentalidad diplomática se formó en la búsqueda del equilibrio multilateral y, en aquel momento (1950), ese equilibrio se volvió bipolar. En la región de Europa Occidental, según San Tiago Dantas (2014: 57-87), Occidente aplica mayores esfuerzos militares, diplomáticos, económicos, y allí aún podía surgir una tercera fuerza entre las dos superpotencias. La aparición de la OTAN estaba vinculada para él al ejercicio del veto por parte de la Unión Soviética en el Consejo de Seguridad de la ONU y a las intenciones de los Estados Unidos de dificultar las pretensiones neutralistas europeas.

Distinguía la Junta de Defensa Interamericana, de carácter intergubernamental, del Consejo del Atlántico Norte, cuyo papel es más técnico y supranacional. Llamaba la atención sobre el "proceso de aglutinación económico-político" en Europa, diciendo que era esencial la participación de Alemania en términos de infraestructura y subrayando que los británicos se inclinaban más por la idea de una comunidad atlántica que por un movimiento regional europeo. En sus conclusiones, afirmaba que se estaba yendo hacia una etapa de superación de la vida internacional basada en naciones, hacia una coordinación de defensa en organismos e integraciones de las regiones. Es un texto que analizaba la situación, con especial hincapié en la relación entre la seguridad regional y el Atlántico Norte.

El último texto (Dantas, 2014: 89-114) a destacar está más conectado a la geoeconomía y se refiere a la inversión extranjera. En relación con las inversiones debía evitarse tanto el intervencionismo económico como la economía de mercado pura, a la vez que una política de inversiones debería crear condiciones favorables para la formación y aplicación del capital nacional y para la entrada de capital extranjero, sea público o privado, dirigido y espontáneo. La libertad de circulación del capital debe presentarse junto con la igualdad de oportunidades, con una preferencia

12 Guerreiro Ramos en la arena "isebiana" no estaba de acuerdo con Jaguaribe, en la arena de PTB estaba en desacuerdo con San Tiago Dantas, y en la arena sociológica tendría como gran rival a Florestan Fernandes. 
por las inversiones con función económico-social, con la defensa de los intereses públicos fundamentales y con restricciones eventuales sobre la exportación de ganancias. En proposiciones generales, en las cuales hay un esbozo de lo que debería fundamentar una futura ley de inversiones, se establecían como requisitos el aumento de la productividad, la atracción de capitales, la preparación de técnicos y la reciprocidad en las cooperaciones.

San Tiago Dantas, Josué de Castro y los "isebianos" presentan un pensamiento macroeconómico más cerca de las tesis cepalinas del desarrollo, mientras que Juárez Távora, por ejemplo, y algunos "esguianos" presentan un razonamiento económico más marginalista, microeconómico, con énfasis en la oferta y la demanda.

\section{Conclusión}

Repasemos ahora los caminos recorridos por ese texto. En principio se presentó la geopolítica "clásica" de los centros del poder, para tratar brevemente a continuación la producción realizada en el Sur Global. De esta manera, se pueden sacar conclusiones sobre las diferencias y algunas afinidades entre determinadas escuelas de pensamiento. El panorama trazado ha servido para que, al glosar más detenidamente las corrientes brasileñas, fuese posible comprender cómo los autores de Brasil se relacionaron con sus pares, ya sea al Norte o al Sur. Con el tiempo, la nomenclatura cambió para conceptuar el mismo conjunto de países: de colonizados a Tercer Mundo y, a continuación, a subdesarrollados, que, más recientemente, se denominan Sur Global. Pese a que hoy en día se piensa más sobre las estrategias de esos países para lograr influencia regional y/o global (Braveboy-Wagner, 2016), durante mucho tiempo, los contextos unipolares o multipolares hacían esa investigación difícil, pues no se comprendía la relevancia de esos países. Cuanto más complejo se vuelve el escenario global de hoy, más importante es comprender sus tendencias (geo)políticas.

Así, sabiendo que hay dos cuerpos distintos de pensamiento en la Geopolítica brasileña —uno "clásico/central" y uno "no hegemónico/periférico"—, se intentó presentarlos para comprender globalmente cómo un grupo de intelectuales, en lucha entre ellos, produjeron ideas originales. Según Pocock (2009), la tradición es una serie de acciones repetidas, autorizadas por el conocimiento de los actos anteriores. Son modos institucionalizados de transmitir comportamientos, cuyas conciencias de tiempo, institucionalización y autoridades pueden variar. De hecho, no existe una sola tradición en términos de producción geopolítica.

Ni siquiera podemos esperar que el mismo texto sea leído y juzgado de la misma forma, porque existen ideas sobre el papel, pero las maneras en que los textos pasan a los actos de los hombres de Estado son totalmente diferentes. En Brasil, se pueden distinguir dos grupos productores de "tradiciones": el que más se conoce es el de los "opus populi", especialmente los militares, pero hemos intentado presentar la importancia de los "verbum populi", especialmente los intelectuales. No podemos afirmar que sean grupos sólidos y bien tramados, sino más bien tipos ideales que ayudan a aclarar las diferencias entre los dos grupos.

Por eso se presenta en ambos casos su "linaje", siguiendo aquí el concepto de "tradición". Cada tradición/linaje persigue sus propios objetivos para la nación, y hay afinidades y conflictos con otras. Luego, siempre habrá conflictos de ideas. El 
factor "agonía" siempre estará presente en la perspectiva de ese trabajo. La particularidad de Brasil está en el tipo de disputas entre esas escuelas de pensamiento y para comprenderlo se hizo necesario revisar determinadas ideas de aquel tiempo. Con eso, se realizó una revisión de los textos de forma sintética, porque se abordó un periodo de mucha producción geopolítica con mucha relevancia. La presentación de los textos se guio por el impacto que ha tenido y tiene cada uno de los textos seleccionados - ya sea en el Brasil, ya sea en las tradiciones que no son brasileñasen relación a prácticas y pensamientos de hoy en día. Por lo tanto, la investigación se propuso hacer una especie de arqueología de orígenes de lo que hoy se dice y se hace, en especial en geopolítica.

A veces, algunos "populi" tuvieron contacto y mantuvieron relaciones muy educadas, aunque con profundos desacuerdos. De hecho, existían distintas concepciones de la inserción internacional, o mejor dicho, distintos paradigmas en el país en la época analizada: el de la alianza con Estados Unidos y el de la ampliación "globalista" de relaciones (Lima, 1994). Estas distintas concepciones ilustran disputas internas por el poder en el país, así como influencias y presiones externas. Pues, como era un ambiente plural y democrático, la política exterior se basaría en la interacción entre actores organizados horizontal y verticalmente, como son, como norma general, todas las otras políticas públicas (Milani \& Pinheiro, 2013). Por lo tanto, la "gran estrategia" que Brasil podría tener en los años posteriores de 1964 traería consigo los antecedentes, que son esas disputas entre titanes de la geopolítica de Brasil. Las tradiciones encuadradas en ese opúsculo estaban situadas en el terreno agonal.

Por un lado, la primacía de la seguridad, del orden, de la unidad e integridad territoriales, de la actividad en la región de América del Sur, de la verdadera interpretación de obras clásicas internacionales y de la experiencia profesional guiaron algunas escrituras. Desde otro ángulo, la experiencia en la escritura guio lo que deberían hacer los profesionales, la producción endógena, las acciones alrededor del mundo, la urgente necesidad de abordar cuestiones que trascienden los límites de los territorios, el nacionalismo y la primacía del desarrollo. Queda aún por responder a la pregunta: ¿sería posible, dentro de este marco, el consenso? Ambas tendencias querían superar los retrasos, principalmente económicos, proponían más relevancia y responsabilidad del país - ya sea en su región, ya sea en otras partes-, veían la necesidad de estudiar la propia realidad y, sin duda, ambas tenían tanto grupos moderados como radicales. Además, cada uno a su manera acogió las tradiciones de otras partes más conocidas en la época.

Mientras los "opus populi" vislumbraron soluciones a partir de lo que vivían cada día, los "verbum populi" pensaban modos concretos para resolver cuestiones que conocían, al menos de forma abstracta. El modo de construir el pensamiento marca su propio discurrir, pues, en general, a los que conocían más los primeros era a personas vinculadas a la toma de decisiones, mientras que los que más consumían las ideas de los segundos estaban situados en instituciones al estilo de las universidades. Al revisar la época se constata una profunda indecisión sobre el orden institucional, y eso se refleja en las constantes crisis. Pero había certezas, como la de que era imperativo cambiar las condiciones adversas que, de hecho, impedían al Brasil poder ser influyente. ¿Qué consensos serían posibles hoy en otros países y qué agonías o tradiciones hay? ¿Cómo podemos comprenderlos teniendo en mente la geopolítica? Permanecen las preguntas. Las tradiciones no mueren y tal vez no haya 
solo dos tradiciones a luchar entre ellas. Tal vez la lección del análisis de un tiempo que se fue, de pensadores ya muertos, es que mirar hacia el pasado puede ayudar a comprender las actuales complejidades geopolíticas, en Brasil o fuera de él.

\section{Bibliografía}

Aguiar, João Catraio (2015) "Since Imperial Viscounts until Republican Barons: "region" at the conservative diplomatic lineage at Itamaraty (1840s to 1930s)". Revista NEIBA, Cadernos Argentina-Brasil, vol. IV, Dossiê Regionalismos-Simpori, 24-33.

Arruda, Antônio de (1983) A Escola Superior de Guerra: história de sua doutrina. Brasília: INL / São Paulo: GRD.

Ayoob, Mohammed (1998) "Subaltern Realism: International Relations Theory meets the Third World", en S. G. Neuman (ed.) International Relations Theory and the Third World. Nueva York: St. Martins's Press, 31-54.

Backheuser, Everardo (1933) Problemas do Brasil (estrutura geopolítica): o "espaço". Rio de Janeiro: Grupo Editor Omnia.

Beigel, Fernanda (2013) "Centros y periferias en la circulación internacional del conocimiento". Nueva Sociedad, núm. 245, 110-123.

Bilac, Olavo (1965) [1915-1916] A Defesa Nacional (discursos). Rio de Janeiro: Biblioteca do Exército.

Bôas, Glaucia Villas (2006) Mudança provocada: passado e futuro no pensamento sociológico brasileiro. Rio de Janeiro: FGV.

Braveboy-Wagner, Jacqueline Anne (ed.) (2016) Diplomatic Strategies of Nations in the Global South: The Search for Leadership. Nueva York: Palgrave Macmillan.

Cahnman, Werner (1942) "Methods of Geopolitics". Social Forces, vol. 21, núm. 2, 147154.

Cairo, Heriberto (2011) "La Geopolítica como "ciencia del Estado": el mundo del general Haushofer". Geopolitica(s). Revista de estudios sobre espacio y poder, vol. 3, núm. 2, 337-345.

Castro, João Augusto de Araújo (1982) "O Poder Nacional. Limitações de Ordem Interna e Externa”, en R. Amado (ed.) Araújo Castro. Brasília: Editora UNB, 3-24.

Castro, Josué de (1946) Geografia da fome. Rio de Janeiro: O Cruzeiro.

Castro, Josué de (1955) [1950] Geopolítica da Fome: ensaios sobre os problemas da alimentação e de população do mundo. São Paulo: Editora Casa do Estudante do Brasil.

Césaire, Aimé (1955) Discours sur le colonialisme. Paris: Éditiones Présence Africaine.

Guevara de la Serna, Ernesto "Che" (1980) [1961] A guerra de guerrilhas. São Paulo: Edições Populares.

Clausewitz, Carl von (1988) [1832] Da Guerra. Lisboa: Publicações Europa-América.

Conduru, Guilherme Frazão (2013) "José Carlos Macedo Soares: liberal, nacionalista e democrata", en J. V. de Sá Pimentel (ed.) Pensamento diplomático brasileiro: formuladores e agentes da politica externa (1750-1964). Volume III. Brasília: FUNAG, 753-797.

Corbisier, Roland (1960) Brasilia e o desenvolvimento nacional. Rio de Janeiro: ISEB.

Costa, Wanderley Messias da (2013) Geografia Política e Geopolítica. São Paulo: EDUSP.

Criekemans, David (2011) "Réhabilitation et rénovation en matière de pensée géopolitique". L'Espace Politique, núm. 12 [Puesto en línea el 11 de febrero de 2011. URL: <http://espacepolitique.revues.org/index1723.html>. Consultado el 15 de febrero de 2011]. 
Dantas, Francisco Clementino de San Tiago (2014) Poder nacional, cultura politica e paz Mundial: Conferências de San Tiago Dantas na Escola Superior de Guerra (1951-1962). Rio de Janeiro: Escola Superior de Guerra.

Douhet, Giulio (1942) [1921] The Command of The Air. Nueva York: Coward-McCann.

Fanon, Frantz (2003) [1961] Los condenados de la tierra. México, D. F.: FCE.

Ferreira, Oliveiros (1979) "A Escola Superior de Guerra no quadro do pensamento político brasileiro”, en A. Crippa (ed.) As idéias politicas no Brasil, Volume II. São Paulo: Editora Convívio, 249-288.

Garcia, Afrânio (2006) “Circulación y formación de una «escuela de pensamiento» latinoamericana (1945-2000)". Prismas, revista de historia intelectual, núm.10, 11-35.

Gonçalves, Williams (1984) O pensamento estratégico brasileiro - o discurso de Golbery. Disertación para Maestría en Filosofía), Pontifícia Universidade Católica do Rio de Janeiro (PUC-Rio), Rio de Janeiro.

Gottmann, Jean (1951) “Geography and International Relations”. World Politics, vol. 3, núm. 2, 153-173.

Guimarães, Samuel Pinheiro (2015) “A política externa de Helio Jaguaribe”, en S. E. Moreira Lima (ed.). Visões da Obra de Helio Jaguaribe. Brasília, D. F.: FUNAG, 81-106.

Haushofer, Karl (2012) [1927] “Los fundamentos geográficos de la política exterior”. Geopolitica(s). Revista de estudios sobre espacio y poder, vol. 3, núm. 3, 329-336.

IBESP (1956) "Para uma Política de Desenvolvimento Nacional". Cadernos de Nosso Tempo, núm. 5, 47-188.

Ingenieros, José (2008) [1913] El hombre mediocre. Buenos Aires: Losada.

Ingrao, Christian (2015) Crer e Destruir: os intelectuais na máquina de guerra da SS nazista. Rio de Janeiro: Zahar.

Jaguaribe, Helio (1957) Condições institucionais do desenvolvimento. Rio de Janeiro: ISEB. Jaguaribe, Helio (2005) [1958] O nacionalismo na atualidade brasileira. Rio de Janeiro: Cândido Mendes.

Lacoste, Yves (2011a) [1976] "Investigación sobre el bombardeo de los diques del río Rojo (Vietnam, verano 1972). Método de análisis y reflexiones de conjunto." Geopolítica(s). Revista de estudios sobre espacio y poder, vol. 2, núm. 2, 313-337.

Lacoste, Yves (2011b) "Del razonamiento geográfico, táctico y estratégico al razonamiento geopolítico: los comienzos de Hérodote." Geopolitica(s). revista de estúdios sobre espacio y poder, vol. 2, núm. 2, 339-342.

Lefebvre, Henri (1974) “La production de l'espace”. L'Homme et la société, núm. 31-32, 1532.

Lefebvre, Henri (2012) [1976] "El Estado Moderno.” Geopolítica(s). Revista de estudios de espacio y poder. vol. 3, núm. 1, 137-149.

Lemos, Thiago Tremonte de (2013) "Um começo germanófilo: 100 anos de Revista A Defesa Nacional". Boletim Meridiano 47, vol. 14, núm. 136, 33-38.

Lima, Maria Regina Soares de (1994) "Ejes analíticos y conflicto de paradigmas en la política exterior brasileña”. América Latina Internacional, vol. 1, núm. 2, 27-46.

Lumumba, Patrice (2013) Recueil de textes (Introduit par Georges Nzongola-Ntalaja). Ginebra: C.E.T.I.M.

Lynch, Christian (2013) "Por que pensamento e não teoria? A imaginação político-social brasileira e o fantasma da condição periférica (1880-1970)". DADOS - Revista de Ciências Sociais, vol. 56, núm. 4, 727-767. 
Mackinder, Halford (2011) [1904] "El pivote geográfico de la historia”. Geopolítica(s). Revista de estudios sobre espacio y poder, vol. 1, núm. 2, 301-319.

Mahan, Alfred. (2013) [1890] “Análisis de los elementos del poder naval”. Geopolítica(s). Revista de estudios sobre espacio y poder, vol. 4, núm. 2, 305-334.

Maia, João Marcelo Ehlert (2008) A terra como invenção: o espaço no pensamento social brasileiro. Rio de Janeiro: Jorge Zahar.

Milani, Carlos \& Pinheiro, Letícia (2013) "Política Externa Brasileira: os desafios de sua caracterização como política pública". Contexto Internacional, vol. 35, núm. 1, 11-41.

Miyamoto, Shiguenoli (1996) Geopolitica e Poder no Brasil. São Paulo, Papirus.

Moraes, Antonio Carlos Robert (2005) Geografia: pequena história crítica. São Paulo: Annablume.

Ó Tuathail, Gearóid (1994) "Critical geopolitics and development theory: intensifying the dialogue". Transactions of the Institute of British Geographers, vol. 19, núm. 2, 228-233.

Pereira, Alexsandro Eugenio (2005) “Organização, estrutura e trajetória do ISEB”, en C. N. de Toledo (ed.). Intelectuais e política no Brasil: a experiência do ISEB. Rio de Janeiro: Revan, 253-260.

Pocock, John G. A. (2009) "Time, institutions and action: an essay on traditions and their understanding”, en J. G. A. Pocock (ed.) Political Thought and History: Essays on Theory and Method. Cambridge: Cambridge University Press, 187-216.

Prébisch, Raúl (1971) [1963] Hacia una dinámica del desarrollo latinoamericano. México, D. F.: FCE.

Ramos, Alberto Guerreiro (1957) Ideologias e segurança nacional. Rio de Janeiro: ISEB.

Ratzel, Friedrich (2011) [1896] "Las leyes del crecimiento espacial de los Estados. Una contribución a la Geografía científico-política". Geopolítica(s). Revista de estudios sobre espacio y poder, vol. 2, núm. 1, 135-156.

Rodó, José Enrique (1985) [1900] Ariel. Motivos de Proteo. Caracas: Biblioteca Ayacucho.

Silva, Golbery do Couto e (1967) Geopolitica do Brasil. Rio de Janeiro: José Olympio.

Silva, Golbery do Couto e (1981) [1955] Planejamento estratégico. Brasília, D. F.: Editora Universidade de Brasília.

Sodré, Nelson Werneck (1978) A verdade sobre o ISEB. Rio de Janeiro: Avenir.

Spykman, Nicholas (1938a) "Geography and Foreign Policy, I". The American Political Science Review, vol. 32, núm. 1, 28-50.

Spykman, Nicholas (1938b) "Geography and Foreign Policy, II". The American Political Science Review, vol. 32, núm. 2, 213-236.

Spykman, Nicholas (2008) [1942] America's strategy in world politics: the United States and the balance of power. New Brunswick: Transaction Publishers.

Távora, Juarez (1955) Petróleo para o Brasil. Rio de Janeiro: José Olympio.

Távora, Juarez (1956) Produção para o Brasil. Rio de Janeiro: José Olympio.

Távora, Juarez (1958) Átomos para o Brasil. Rio de Janeiro: José Olympio.

Távora, Juarez (1959) Organização para o Brasil. Rio de Janeiro: José Olympio.

Távora, Juarez (1962) Uma política de desenvolvimento para o Brasil. Rio de Janeiro: José Olympio.

Torres, Alberto (1914) A Organização Nacional. Rio de Janeiro: Imprensa Nacional.

Travassos, Mario (1935) [1931] Projeção continental do Brasil. São Paulo: Companhia Editora Nacional. 
Vargas, João Augusto Costa (2008) Uma esplêndida tradição: João Augusto de Araújo Castro e a política exterior do Brasil. Disertación de Maestría en Diplomacia, Instituto Rio Branco, Brasília.

Vasconcelos, José (1948) [1925] La raza cósmica. México D. F.: Espasa Calpe.

Vianna, Francisco José de Oliveira (2005) [1920] Populações Meridionais do Brasil. Brasília, D. F.: Senado Federal.

Wallerstein, Immanuel (1982) "World-Systems Analysis: Theoretical and Interpretative Issues", en T. Hopkins y I. Wallerstein (eds.) World-Systems Analysis: Theory and Methodology. Londres: SAGE, 91-103. 